\title{
Denosumab treatment of inoperable or locally advanced giant cell tumor of bone
}

\author{
ANETA BORKOWSKA ${ }^{1 *}$, TOMASZ GORYN ${ }^{2 *}$, ANDRZEJ PIEŃKOWSKI ${ }^{2}$, MICHAŁ WĄGRODZKI $^{3}$, \\ EWELINA JAGIEŁŁO-WIECZOREK ${ }^{2}$, PAWEŁ ROGALA ${ }^{2}$, MILENA SZACHT ${ }^{2}$ and PIOTR RUTKOWSKI ${ }^{2}$
}

\author{
Departments of ${ }^{1}$ Radiation Oncology, ${ }^{2}$ Soft Tissue/Bone Sarcoma and Melanoma and ${ }^{3}$ Pathology, \\ Maria Skłodowska-Curie Memorial Cancer Center and Institute of Oncology, 02-781 Warsaw, Poland
}

Received February 28, 2016; Accepted July 12, 2016

DOI: $10.3892 / 01.2016 .5246$

\begin{abstract}
Giant cell tumor of bone (GCTB) is an osteolytic, locally aggressive tumor that rarely metastasizes and typically occurs in the bones. At present, the primary treatment for GCTB is curettage with local adjuvants. Giant cells express receptor activator of nuclear factor- $\mathrm{\kappa B}$ ligand (RANKL). Denosumab, a RANKL inhibitor appears to present an effective therapeutic option in advanced cases of GCTB. The aim of the present study was to confirm the efficacy of denosumab in large group of patients with locally advanced GCTB. A total of 35 patients with histologically confirmed GCTB that were treated with denosumab with no participation in clinical trials between May 2013 and September 2015 were included in the present study. Denosumab treatment was administered until complete tumor resection was feasible or tumor progression or unacceptable toxicity had occurred. The mean denosumab treatment duration was 7.4 months. A total of 17 patients received surgery following denosumab treatment: 11 patients underwent wide en bloc resection with prosthesis implantation in 10 cases and 6 patients were treated with intralesional curettage. Tumor progression was observed in 2 patients that underwent intralesional curettage without prosthesis implantation. In addition, tumor progression was observed during denosumab treatment in 2 patients that had previously undergone radiotherapy. The overall 1-year progression-free survival rate was $92.8 \%$. Thus, for patients with advanced, unresectable, progressive or symptomatic pretreated GCTB, denosumab provides a therapeutic option not previously available, which has become the standard therapy in multidisciplinary management of GCTB.
\end{abstract}

Correspondence to: Professor Piotr Rutkowski, Department of Soft Tissue/Bone Sarcoma and Melanoma, Maria Sklodowska-Curie Memorial Cancer Center and Institute of Oncology, 5 Roentgena Street, 02-781 Warsaw, Poland

E-mail: piotr.rutkowski@coi.pl

*Contributed equally

Key words: giant cell tumor of bone, denosumab, receptor activator of nuclear factor- $\kappa \mathrm{B}$,receptor activator of nuclear factor- $\mathrm{\kappa} \mathrm{B}$ ligand

\section{Introduction}

Giant cell tumor of bone (GCTB) is a relatively rare, locally aggressive benign osteolytic tumor that most commonly affects young adults. GCTB accounts for $4-10 \%$ of all biopsy-analyzed primary bone tumors (1-3).

The majority of lesions (85\%) develop at the epiphyses of long bones, but may also occur in the sacrum, vertebral body and occasionally in the small bones of the hands and feet (4). In a small number of cases (1-4\%), pulmonary metastasis has been reported $(5,6)$. Spontaneous transformation to an overt malignancy occurs in $<10 \%$ of cases $(2,3)$.

The most common symptoms of GCTB include pain, swelling, impaired mobility of the joints, pathological fractures of involved bones and deformation of the bone (2-4). On radiography, GCTB most commonly presents as a nonsclerotic, osteolytic lesion with clearly defined margins. In addition, pathological fractures located in the metaphysis of long bones that extend to the epiphysis in the subarticular region are common $(3,7)$.

Core needle biopsy, open biopsy or intra-operative frozen section analysis are performed to establish the final diagnosis prior to or during surgery, due to the aggressive nature of the tumor and its tendency for malignant transformation (8-10). Microscopically, GCTB is composed of neoplastic and reactive cell populations. The cell population is composed of osteoclast-like multinucleated giant cells, rounded mononuclear histiocytic cells and round/ovoid mononuclear stromal cells, which represent the proliferative neoplastic component $(8,11-13)$. The stromal cells grow in a syncytium, exhibit ill-defined cell borders with little eosinophilic cytoplasm and variable degrees of mitotic activity. Foci of necrosis and vascular invasion may also be present. Tumors may demonstrate benign fibrous histiocytoma-like areas, hemosiderin deposits, secondary aneurysmal bone cyst changes (10-15\% of tumors) and reactive bone formation $(6,9,11,14)$.

Regarding the functional molecular biology of GCTB, receptor activator of nuclear factor- $\kappa \mathrm{B}$ ligand (RANKL) is highly expressed by neoplastic mononuclear mesenchymal stromal cells (15-17), whereas RANK is expressed on osteoclast-like cells, which are recruited secondarily in the tumor, but are responsive to the aggressive osteolytic activity (2). RANK-RANKL interactions, which are involved 
in normal bone formation and function, and macrophage colony-stimulating factor exhibit important functions in osteoclastogenesis by stimulating the recruitment of osteoclastic cells from blood-born mononuclear osteoclast precursor cells that differentiate into multinucleated osteoclast-like giant cells $(12,18-20)$. This is supported by the observation that giant cells in GCTB exhibit an osteoclast-like phenotype. Thus, these consistent findings confirm the involvement of imbalanced RANKL and RANK expression and dysregulation of the RANKL-RANK-osteoprotegerin signaling pathway in the pathogenesis of GCTB and induction of bone over-resorption at the tumor site.

A recent study identified the driver $H 3 F 3 A$ gene mutation in $92 \%$ of GCTBs, which occurred exclusively in stromal cells (21).

Primary malignancy in GCTB is observed at initial diagnosis as an area of morphologically distinct malignant mesenchymal tumor cells within an otherwise conventional GCTB. In secondary malignant GCTB, sarcomas arise subsequent to previous radiation or surgical treatment and the pre-existing GCTB is not always evident $(8,11)$.

One study hypothesized that the histological features of GCTB indicate subsequent behavior and thus may predict prognosis while providing valuable guidance in treatment (22). GCTB is classified into 3 types: Grade I, tumors exhibit sparse stroma and giant cells predominate; Grade II (atypical/borderline GCTB, identified using $H 3 F 3 A$ mutation testing), tumors composed of a smaller giant cell population with atypical cells or single atypical mitoses in the more pronounced stroma; Grade III, tumors represent overt malignant sarcoma (occasionally low-grade) (22). This grading system primarily shows continuum between histologically benign and sarcomatous tumors, underscoring the presence of borderline lesions, which have worrisome features at imaging examinations, but provided they have a positive $\mathrm{H} 3 \mathrm{~F} 3 \mathrm{~A}$ mutation status, still respond well to denosumab treatment. The majority of GCTB cases are classified as grade I, however, $\leq 20 \%$ of cases, even in the absence of histological malignant traits, invade the cortex and directly extend into adjacent soft tissues. This results in major discrepancies between histological tumor grade and radiological stage (23). Radiological staging is considered more important than histological grading for predicting the clinical behavior of GCTB, including recurrence and metastatic potential $(2,5,7)$.

It is also difficult to differentiate GCTB from other mimicking benign bone lesions, such as aneurysmal bone cyst, giant cell reparative granuloma, brown tumor of hyperparathyroidism, benign fibrous histiocytoma or chondroblastoma, as well as malignant lesions, such as giant cell rich or teleangiectatic osteosarcoma and undifferentiated pleomorphic sarcoma (24).

The primary treatment for GCTB is surgery, however local recurrence or metastasis may occur. The type of surgical treatment selected depends on the feasibility of curettage compared with resection and the risk of local recurrence. The most common surgical treatment is local curettage, which exhibits varying rates of local recurrence depending on the use of local adjuvants such as phenol, liquid nitrogen and polymethylmethacrylate cement, described as improved (12-27\% of local recurrence) compared with local controls. If local adjuvants are not utilized, the mean recurrence rate is higher $(21-65 \%)(2,7)$. Furthermore, the risk of local recurrence is markedly increased by soft tissue extension (20-25\% of all GCTBs) $(7,25)$. More aggressive forms of surgical treatment, such as en bloc wide resection, may potentially decrease the risk of local recurrence (3), however, this procedure may lead to reconstruction problems and impaired functional anatomy. Prosthesis may be used for local treatment, which results in a good quality of life, however, the risk of local recurrence following this procedure is unclear, and possible complications, particularly in relatively young patients affected by GCTB, must be considered when planning therapy $(26,27)$. En bloc resection should be considered in cases of multiple recurrent GCTB, impossible joint salvage, extensive cortex destruction (insufficient cortex left to curette) and extensive soft tissue involvement $(2,7)$.

Moderate-dose radiotherapy (40-55 Gy) has previously been demonstrated as an effective primary treatment in unresectable GCTB and in cases of residual or recurrent disease whereby surgery would result in unacceptable morbidity, however, with the introduction of RANKL inhibitors this must be redefined and limited to individualized cases. In addition, the risk of malignant transformation after radiotherapy is $0-5 \%$ (3).

Bisphosphonates and interferon- $\alpha$ have also been used in GCTB treatment. Bisphosphonates inhibit osteoclast activity and promote their apoptosis, which prevents bone resorption. A previous case study reported that biphosphonate treatment reduced the local recurrence rate of GCTB from $30 \%$ in the control group to $4.2 \%$ in the bisphosphonates-treated group (28).

Recently, the RANKL inhibitor, denosumab, has been investigated as a treatment for advanced GCTB $(1,29)$. Denosumab is a human monoclonal antibody that binds to RANKL and prevents RANKL activation, thereby inhibiting the maturation of osteoclasts $(29,30)$. The high efficiency of GCTB denosumab treatment has been confirmed in two phase II studies. An open-label phase II study reported an objective response to denosumab therapy in $86 \%$ of patients, whereby an objective response was defined as $>90 \%$ elimination of giant cells on histopathological evaluation or no radiographical progression of the lesion (31). A second, larger study revealed that $96 \%$ of surgically unsalvageable GCTB patients exhibited no disease progression during treatment (median follow-up time, 13 months) and acceptable drug toxicity (31-33). Denosumab treatment should be continued until radical resection of the tumor is possible or progression or unacceptable toxicity has occurred.

The present study is the largest single center analysis of denosumab treatment in GCTB patients used in routine practice to date.

\section{Materials and methods}

Patients and procedures. A total of 35 patients with histologically confirmed GCTB treated with denosumab in a referral center (Maria Skłodowska-Curie Memorial Cancer Center and Institute of Oncology) without participation in clinical trials between May 2013 and September 2015 were included in the study. All pathological diagnoses were reviewed by a 
Table I. Demographic and clinicopathological characteristics of 35 GCTB denosumab-treated patients included in the present study.

\begin{tabular}{|c|c|}
\hline Parameter & Value \\
\hline \multicolumn{2}{|l|}{ Gender, n (\%) } \\
\hline Female & $21(60)$ \\
\hline Male & $14(40)$ \\
\hline Median age, years (range) & $32(19-74)$ \\
\hline \multicolumn{2}{|l|}{ GCTB disease type, n (\%) } \\
\hline Unresectable primary tumor & $9(26)$ \\
\hline Resectable high-risk primary tumor & $26(74)$ \\
\hline \multicolumn{2}{|l|}{ Prior GCTB therapies, n (\%) } \\
\hline Biopsy only & $24(68)$ \\
\hline RT & $4(11)$ \\
\hline Subtotal resection & $3(9)$ \\
\hline Radical resection & $3(9)$ \\
\hline Surgery + adjuvant RT & $1(3)$ \\
\hline \multicolumn{2}{|l|}{ Tumor localization, n (\%) } \\
\hline Lower limb & $17(49)$ \\
\hline Tibia & $10(29)$ \\
\hline Femur & $6(17)$ \\
\hline Fibula & $1(3)$ \\
\hline Upper limb & $11(31)$ \\
\hline Humerus & $4(11)$ \\
\hline Radius & $5(14)$ \\
\hline Ulna & $1(3)$ \\
\hline Metacarpal bone & $1(3)$ \\
\hline Axial & $7(20)$ \\
\hline Sacrum & $5(14)$ \\
\hline Ilium & $1(3)$ \\
\hline Ischium & $1(3)$ \\
\hline
\end{tabular}

GCTB, giant cell tumor of bone; RT, radiotherapy.

reference pathologist in our center. Seven cases could not be diagnosed pathologically and thus, mutational status of the $H 3 F 3 A$ gene was tested, which revealed that all patients were positive for the $H 3 F 3 A$ gene mutation.

The lesions were located in the lower limbs in 17 (49\%) patients (49\%), in the upper limbs of 11 patients $(31 \%)$ and the axial skeleton in 7 patients (20\%). All cases were evaluated by a multidisciplinary team (MDT) prior to the start of therapy with denosumab. A total of $24(68 \%)$ patients exhibited primary tumors after diagnostic biopsy, while $11(31 \%)$ patients exhibited recurrent tumors after undergoing previous surgical procedures. A total of 10 (29\%) cases, which were predominantly located in axial locations, were defined as unresectable and 24 patients exhibited locally advanced tumors with soft tissue involvement [grade III, according to radiographic staging systems by Campanacci et al (6)], and the majority of these cases exhibited penetration of the joint, were not suitable for limb-sparing surgery or exhibited an extremely high risk of tumor recurrence.
Table II. Duration of treatment with denosumab in the present study.

\begin{tabular}{lcc}
\hline Group & Patients, $\mathrm{n}$ & $\begin{array}{c}\text { Mean } \\
\text { treatment time, } \\
\text { months (range) }\end{array}$ \\
\hline Total & 35 & $7.4(2-16)$ \\
Surgery & 17 & $7.2(5-12)$ \\
No surgery & 18 & $7.8(2-16)$ \\
\hline
\end{tabular}

Patient demographics and clinicopathological characteristics are shown in Table I. A slight female predominance $(60 \%)$ was observed. The mean age of the patient cohort was 32 years-old (range, 19-74 years-old).

A total of 4 patients had received radiotherapy prior to denosumab treatment. Furthermore, 3 patients had undergone total resection and 3 patients had undergone subtotal resection prior to denosumab treatment. One patient had been treated with surgery and radiotherapy.

All patients received subcutaneous injections of denosumab (120 mg) every 28 days, with additional injections on days 8 and 15 of the first month, in addition to calcium (1,000 mg/day) and vitamin D (400 IU/day) supplements. Treatment was continued until complete tumor resection was feasible (as assessed by the MDT) or tumor progression or unacceptable toxicity had occurred. Adverse events were recorded and graded according to the National Cancer Institute Common Terminology Criteria for Adverse Events (version 4.0) (34). Tumor status was assessed every 3 months by computed tomography or magnetic resonance imaging. In addition, X-rays were performed every 2-3 months.

Written informed consent was obtained from all patients for the publication of this study, and study approval was obtained from the Institutional Review Board of Maria Sklodowska-Curie Memorial Cancer Center and Institute of Oncology (Warsaw, Poland).

\section{Results}

Denosumab treatment. The mean denosumab treatment duration was 7.4 months (median, 7 months) (Table II).

The median treatment time in the patients who underwent surgery after neoadjuvant therapy, but had not received denosumab postoperatively, was 7.2 months (5-12 months). In patients who continued monthly denosumab treatment who had not yet undergone surgery (or those who were considered as definitively unresectable), the median treatment time was 7.8 months (2-16 months) (Table II). A total of $17(49 \%)$ patients at the data cut-off date (study end date of September 2015) had undergone surgery. A total of 15 patients continue to receive treatment with denosumab (two additionally as a salvage therapy following tumor recurrence after surgery). Of the 18 patients who did not undergo surgery, 2 patients developed progression and started chemotherapy, and 16 remain on denosumab treatment. All patients remain alive. 
Table III. Adverse effects exhibited in giant cell tumor of bone patients following treatment with denosumab.

\begin{tabular}{lcc}
\hline Adverse effect & $\begin{array}{c}\text { Grade II toxicity, } \\
\mathrm{n}(\%)\end{array}$ & $\begin{array}{c}\text { Grade III toxicity, } \\
\mathrm{n}(\%)\end{array}$ \\
\hline $\begin{array}{l}\text { Hypophosphatemia } \\
\text { Hypocalcemia }\end{array}$ & $8(23)$ & $1(3)$ \\
\hline
\end{tabular}

No grade IV toxicity was observed.

Table IV. Treatment types administered to patients that underwent surgery following denosumab treatment $(n=17)$.

\begin{tabular}{lr}
\hline Treatment type & Patients, $\mathrm{n}(\%)$ \\
\hline Prosthesis replacement & $10(59)$ \\
No prosthesis replacement & $7(41)$ \\
\hline
\end{tabular}

Adverse events. In general, treatment was well tolerated and no grade IV toxicity was observed. However, 2 patients exhibited grade III toxicity: 1 patient experienced hypophosphatemia after 10 months of denosumab treatment and 1 patient exhibited hypocalcemia after 7 months of treatment with denosumab. A total of 11 patients exhibited grade II adverse events (Table III).

Surgery. Of all denosumab-treated patients, 17 (49\%) patients underwent surgery after denosumab treatment. Wide en bloc resection was performed in 11 patients, with prosthesis implantation in 10/11 cases, while 6 patients underwent intralesional curettage with high-speed burr and allograft or bone cement (Table IV). Patients that underwent prosthetic replacement exhibited a longer median preoperative duration of denosumab therapy when compared with patients undergoing surgery without prosthetic implantation.

Pathological changes. Following therapy with the RANKL inhibitor denosumab, in GCTB en bloc resection specimens, giant cells disappeared, the number of mononuclear tumor cells decreased and bone formation increased (Figs. 1 and 2).

Treatment outcomes. Tumor progression after surgical treatment was observed in 2 patients ( 9 and 11 months after surgery) that underwent intralesional curettage without prosthesis implantation. Both patients were subsequently administered salvage denosumab treatment (Table V).

In addition, tumor progression was observed in 2 patients during denosumab treatment. One patient exhibited progression to osteosarcoma 3 months after initiation of denosumab treatment and thus, chemotherapy with doxorubicin and cisplatin was initiated. The second patient exhibited tumor progression 7 months after the initiation of denosumab therapy, which was confirmed by magnetic resonance imaging and subsequently, pathologically malignant GCTB was diagnosed. This patient underwent amputation and chemotherapy was administered. Both patients had undergone radiotherapy prior to denosumab treatment.
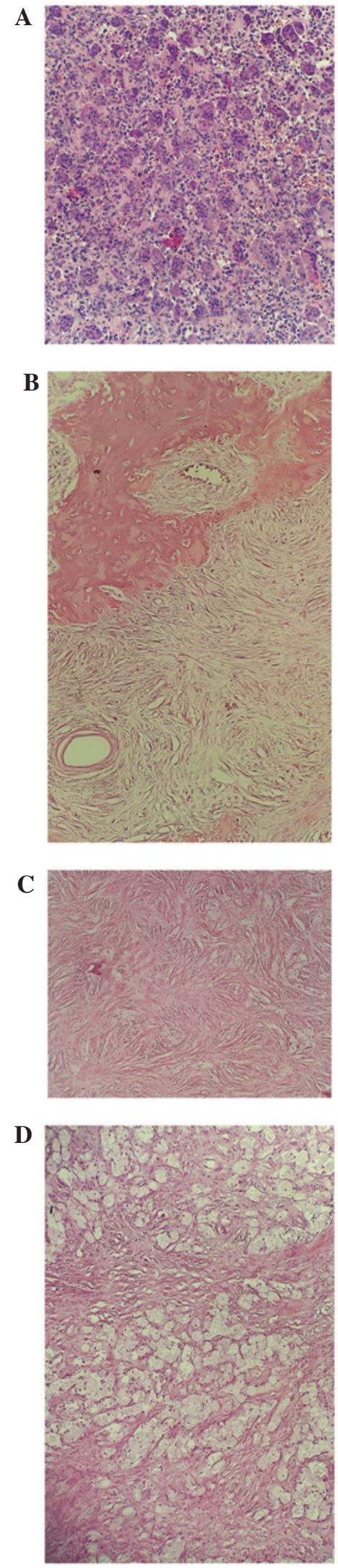

Figure 1. Biopsy specimens obtained from a 32-year-old female with a giant cell tumor of the bone located on the distal meta- and epiphysis of the left femur. (A) Prior to denosumab treatment, evenly dispersed giant cells were observed with little stroma containing small, ovoid stromal cells. After 6 months of denosumab treatment, (B) newly formed, woven bone was deposited at the periphery of the tumor, $(\mathrm{C})$ the centre of the tumor consisted of fibrous connective tissue with small fibroblast-like cells without atypia, and there was a vague storiform pattern to the tissue. (D) Scattered foamy macrophages were observed focally in the lesion. 
Table V. Patient outcomes following surgery with or without prosthesis replacement $(n=17)$.

Outcome Patients with prosthesis replacement, n (\%)

Patients without prosthesis replacement, n (\%)

\begin{tabular}{lcc}
\hline Disease progression & $0(0)$ & $5(71)^{\mathrm{a}}$ \\
No progression & $10(100)$ & $2(29)$ \\
\hline
\end{tabular}

${ }^{\mathrm{a}} 1$ patient exhibited histopathological progression to osteosarcoma during denosumab treatment.

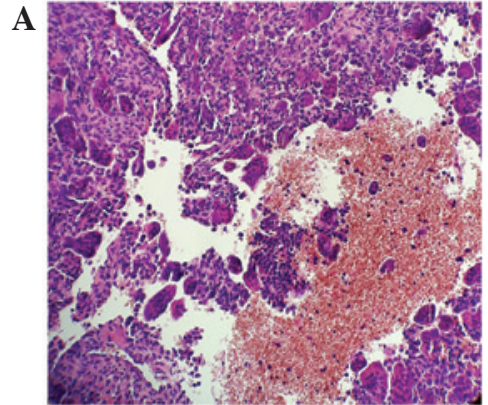

C

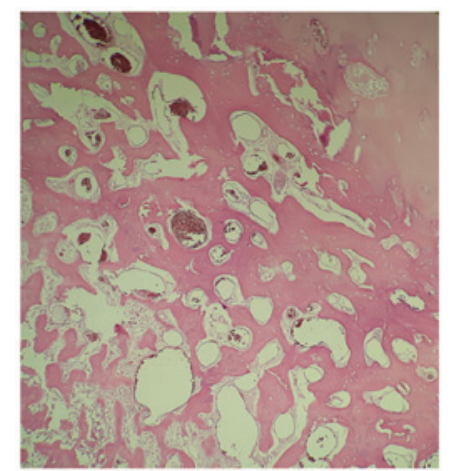

B

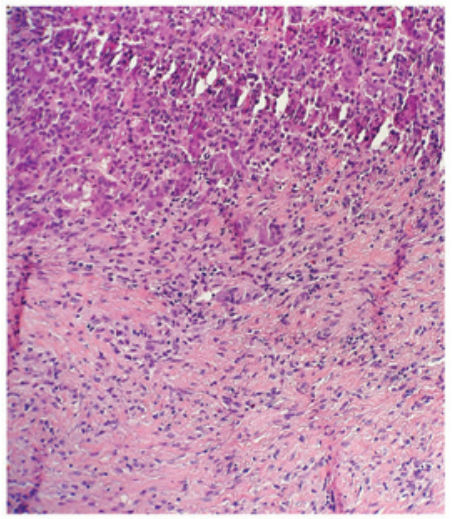

D

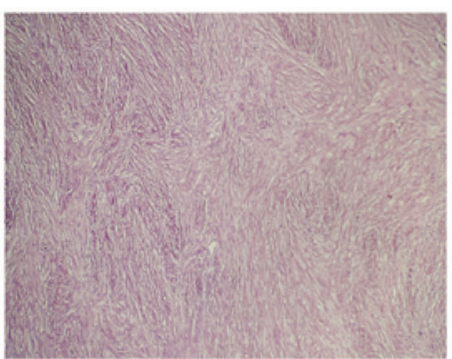

Figure 2. Biopsy specimens obtained from a 39-year old male with giant cell tumor of bone located in distal meta- and epiphysis of the right femur. (A and B) Prior to treatment abundant hemorrhagic areas, with suspected secondary aneurysmal bone cysts, and foci of fibrosis were evident. Diagnosis was subsequently confirmed by H3F3A mutation testing. (C and D) After 12 months of denosumab therapy, fibrosis and prominent, peripheral ossification of the tumor was identified, indicating a good response to denosumab treatment.

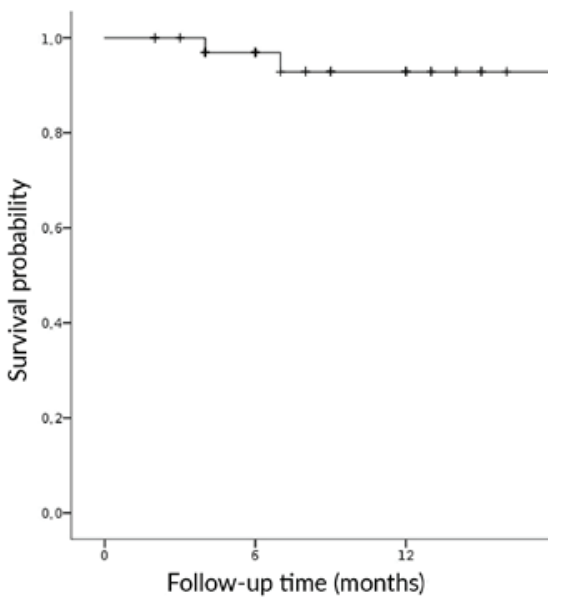

Figure 3. Progression-free survival of giant cell tumor of bone patients treated with denosumab.

The overall 1-year progression-free survival rate was 92.8\% (95\% confidence interval, 83.2-100) (Fig. 3).

\section{Discussion}

The present study summarized the results of denosumab treatment in 35 locally advanced GCTB patients without participation in clinical trials. The results revealed that denosumab exhibits high efficacy with long term responses. This study comprises the largest study of locally advanced GCTB patients without metastasis to receive denosumab in routine practice, and in $\geq 50 \%$ of patients denosumab was administered as a preoperative modality combined with radical local surgery. No patients received denosumab as adjuvant therapy. The primary treatment for GCTB is surgery and the most important challenge in surgical management is the relatively high recurrence rate after curettage (21-65\%) (2,7). Two patients exhibited disease recurrence after curettage, which raises significant concerns regarding curettage after denosumab treatment as the recurrence rate was high $(6.33 \%)$. This indicates that if intralesional surgery is planned after neoadjuvant denosumab, denosumab therapy should be administered for a relatively short period of time ( $\sim 3$ months) as the calcified rim of the tumor may be too thick following 3 months of denosumab 
A

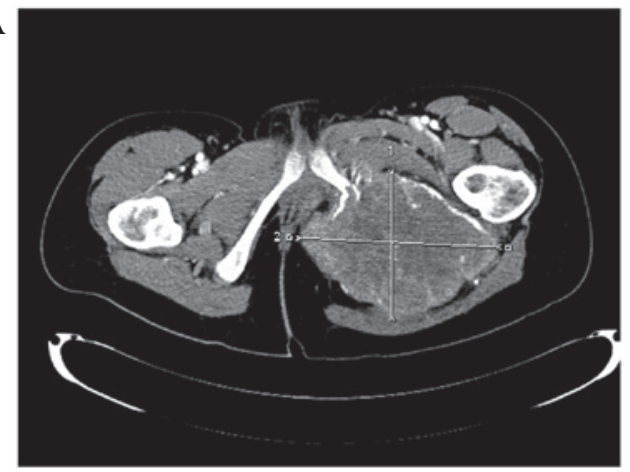

B

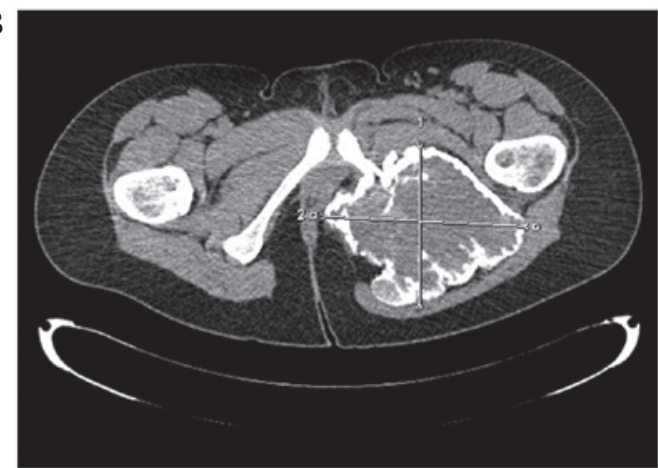

Figure 4. Computed tomography images (A) prior to and (B) following 6 months of denosumab treatment in a case of locally advanced, unresectable giant cell tumor of bone of the pelvis revealing significant calcification of the tumor.

A

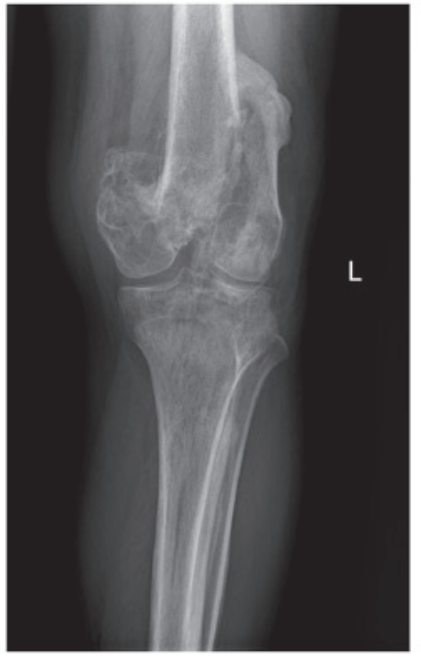

$\mathbf{B}$

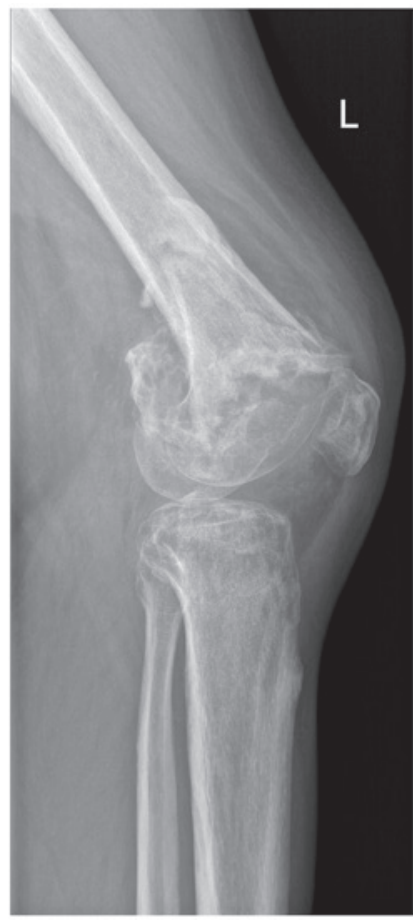

C

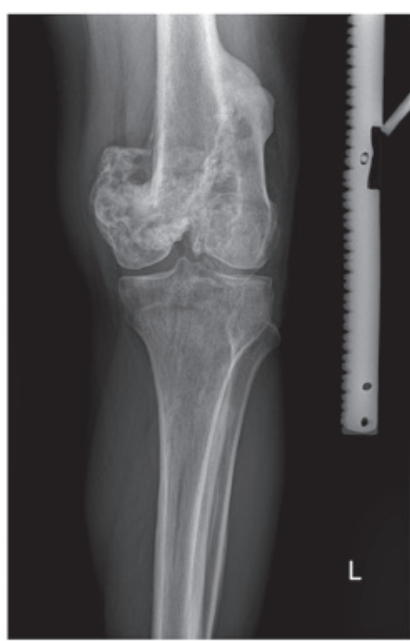

D

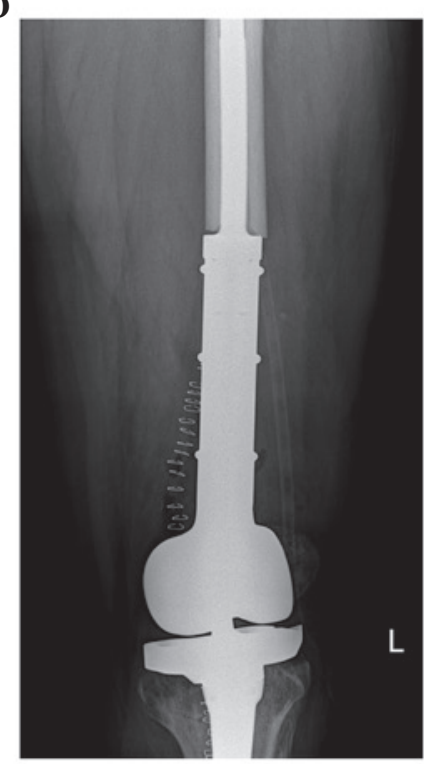

Figure 5. (A) Locally advanced giant cell tumor of the humerus bone on anterior-posterior X-ray view prior to denosumab treatment. (B) The same tumor on lateral X-ray view prior to denosumab treatment. (C) Response on X-ray to denosumab therapy after 7 months of treatment. (D) X-ray after en bloc resection and prosthetic replacement reconstruction following denosumab therapy.

treatment, which would prevent radical curettage of the tumor cells. However, a different situation arises in cases whereby wide radical surgery is planned after denosumab therapy. In the present study, prosthetic replacement was performed in 10/17 cases that underwent surgery as the patients exhibited locally advanced tumors, penetration to the joint or pathological fractures. In such situations calcification of tumors that initially penetrate the soft tissues after denosumab therapy may facilitate or enable radical tumor resection with a low risk of tumor recurrence. Therefore, we postulate that in cases where en bloc resection is planned neoadjuvant therapy should be administered for a longer duration to allow maximal calcification of the tumor (Figs. 4 and 5) and response plateau observed on control imaging. Whether denosumab maintenance is required after radical surgery remains unclear, however, in the present study, no disease recurrence was observed.
A phase II clinical trial assessed 222 patients for possible downstaging with denosumab for planned surgery (35). The majority of patients received adjuvant denosumab for 6 months after surgery. Of the 116 patients who underwent surgery (median postsurgical follow-up time, 13 months), local recurrence occurred in $17(15 \%)$ patients, however, by contrast to the present study, the majority of these patients underwent intralesional curettage.

Furthermore, a number of patients present with inoperable GCTB and thus require life-long denosumab treatment. Although good tolerance of treatment has been reported previously $(33,31)$, data regarding long-term use of denosumab for metastatic/inoperable GCTB is limited. It may be possible to reduce the dose frequency (e.g., to once every 3 months) in patients who have achieved long-term stable disease on monthly denosumab (36). 
In conclusion, denosumab therapy in GCTB is associated with a high rate of tumor response with a good toxicity profile. The results of the present study confirmed that denosumab exhibits excellent efficacy and short-term tolerability. For patients with advanced, unresectable, progressive, or symptomatic heavily pretreated GCTB, denosumab provides a therapeutic option not previously available and thus, has become the standard therapy for multidisciplinary management of advanced/high-risk or unresectable GCTB. Furthermore, the results of the study data suggest that neoadjuvant therapy with denosumab may present a therapeutic option for patients with locally advanced, high-risk tumors to facilitate complete surgical resection or avoid damaging surgery, however, the risk of recurrence after curettage of GCTB following denosumab therapy raises questions regarding the optimal preoperative duration of treatment. This study confirmed the efficacy of denosumab in 35 patients with locally advanced GCTB treated without participation in clinical trials. Complete tumor resection was feasible in $50 \%$ of patients. Therefore, denosumab became the standard therapy for the multidisciplinary management of GCTB.

\section{References}

1. Amanatullah DF, Clark TR, Lopez MJ, Borys D and Tamurian RM: Giant cell tumor of bone. Orthopedics 37: 112-120, 2014.

2. Jagiello-Wieczorek E, Pieńkowski A and Rutkowski P: Denosumab for treating giant cell tumor of bone. Expert Opinion on Orphan Drugs 3: 1219-1229, 2015.

3. Thomas DM and Skubitz KM: Giant cell tumor of bone. Curr Opin Oncol 21: 338-344, 2009.

4. Skubitz KM: Giant cell tumor of bone: Current treatment options. Curr Treat Options Oncol 15: 507-518, 2014.

5. Campanacci M, Baldini N, Boriani S and Sudanese A: Giant-cell tumor of bone. J Bone Joint Surg Am 69: 106-114, 1987.

6. Dominkus M, Ruggieri P, Bertoni F, Briccoli A, Picci P, Rocca M and Mercuri M: Histologically verified lung metastases in benign giant cell tumours - 14 cases from a single institution. Int Orthop 30: 499-504, 2006

7. van der Heijden L, Dijkstra PD, van de Sande MA, Kroep JR, Nout RA, van Rijswijk CS, Bovée JV, Hogendoorn PC and Gelderblom H: The clinical approach toward giant cell tumor of bone. Oncologist 19: 550-561, 2014.

8. Fletcher DM (ed): WHO Classification of Tumours of Soft Tissue and Bone. 4th edition. IARC Press, Lyon, 2013.

9. Greenspan A, Jundt G and Remagen W (eds): Differential Diagnosis in Orthopaedic Oncology. 2nd edition. Lippincott Williams \& Wilkins, Philadelphia, PA, 2007.

10. Biermann JS: Updates in the treatment of bone cancer. J Natl Compr Canc Netw 11 (Suppl 5): S681-S683, 2013.

11. Athanassou NA, Bensal M, Forsyth R, et al: Giant cell tumor of bone. In: WHO Classification of Tumours of Soft Tissue and Bone. Fletcher CDM, Bridge JA, Hogendoorn PCW and Mertens F (eds). IARC Press, Lyon, pp321-324, 2013.

12. Hemingway F, Taylor R, Knowles HJ and Athanasou NA: RANKL-independent human osteoclast formation with APRIL, BAFF, NGF, IGF I and IGF II. Bone 48: 938-944, 2011

13. Wu PF, Tang JY and Li KH: RANK pathway in giant cell tumor of bone: Pathogenesis and therapeutic aspects. Tumour Biol 36 : 495-501, 2015.

14. Chakarun CJ, Forrester DM, Gottsegen CJ, Patel DB, White EA and Matcuk GR Jr: Giant cell tumor of bone: Review, mimics, and new developments in treatment. Radiographics 33: 197-211, 2013.

15. Thomas DM: RANKL, denosumab, and giant cell tumor of bone. Curr Opin Oncol 24: 397-403, 2012.

16. Roux S, Amazit L, Meduri G, Guiochon-Mantel A, Milgrom E and Mariette X: RANK (receptor activator of nuclear factor kappa B) and RANK ligand are expressed in giant cell tumors of bone. Am J Clin Pathol 117: 210-216, 2002.
17. Morgan T, Atkins GJ, Trivett MK, Johnson SA, Kansara M, Schlicht SL, Slavin JL, Simmons P, Dickinson I, Powell G, et al: Molecular profiling of giant cell tumor of bone and the osteoclastic localization of ligand for receptor activator of nuclear factor kappaB. Am J Pathol 167: 117-128, 2005.

18. Liao TS, Yurgelun MB, Chang SS, Zhang HZ, Murakami K, Blaine TA, Parisien MV, Kim W, Winchester RJ and Lee FY: Recruitment of osteoclast precursors by stromal cell derived factor-1 (SDF-1) in giant cell tumor of bone. J Orthop Res 23: 203-209, 2005.

19. Clézardin P: The role of RANK/RANKL/osteoprotegerin (OPG) triad in cancer-induced bone diseases: Physiopathology and clinical implications. Bull Cancer 98: 837-846, 2011 (In French).

20. Forsyth RG, De Boeck G, Baelde JJ, Taminiau AH, Uyttendaele D, Roels H, Praet MM and Hogendoorn PC: CD33+ CD14- phenotype is characteristic of multinuclear osteoclast-like cells in giant cell tumor of bone. J Bone Miner Res 24: 70-77, 2009.

21. Behjati S, Tarpey PS, Presneau N, Scheipl S, Pillay N, Van Loo P, Wedge DC, Cooke SL, Gundem G, Davies H, et al: Distinct H3F3A and H3F3B driver mutations define chondroblastoma and giant cell tumor of bone. Nat Genet 45: 1479-1482, 2013.

22. Huvos AG: Bone Tumors. Diagnosis, treatment and prognosis. 2nd edition. W.B. Saunders, Philadelphia, PA, 1990.

23. Enneking WF (ed): Staging musculoskeletal tumors. In: Musculoskeletal Tumor Surgery. Churchill Livingstone, New York, NY, pp87-88, 1983.

24. Nielsen GP and Rosenberg AE (eds): Diagnostic Pathology : Bone. Amirsys Lippincott Williams \& Wilkins, Philadelphia, PA, 2012.

25. Dufresne A, Derbel O, Cassier P, Vaz G, Decouvelaere AV and Blay JY: Giant-cell tumor of bone, anti-RANKL therapy. Bonekey Rep 1: 149, 2012.

26. Shehadeh A, Noveau J, Malawer M and Henshaw R: Late complications and survival of endoprosthetic reconstruction after resection of bone tumors. Clin Orthop Relat Res 468: 2885-2895, 2010.

27. Jeys LM, Suneja R, Chami G, Grimer RJ, Carter SR and Tillman RM: Impending fractures in giant cell tumors of the distal femur: Incidence and outcome. Int Orthop 30: 135-138, 2006.

28. Tse LF, Wong KC, Kumta SM, Huang L, Chow TC and Griffith JF: Bisphosphonates reduce local recurrence in extremity giant cell tumor of bone: A case-control study. Bone 42: 68-73, 2008

29. Branstetter DG, Nelson SD, Manivel JC, Blay JY, Chawla S, Thomas DM, Jun S and Jacobs I: Denosumab induces tumor reduction and bone formation in patients with giant-cell tumor of bone. Clin Cancer Res 18: 4415-4424, 2012.

30. Steensma MR, Tyler WK, Shaber AG, Goldring SR, Ross FP, Williams BO, Healey JH and Purdue PE: Targeting the giant cell tumor stromal cell: Functional characterization and a novel therapeutic strategy. PLoS One 8: e69101, 2013.

31. Thomas D, Henshaw R, Skubitz K, Chawla S, Staddon A, Blay JY, Roudier M, Smith J, Ye Z, Sohn W, et al: Denosumab in patients with giant-cell tumour of bone: An open-label, phase 2 study. Lancet Oncol 11: 275-280, 2010.

32. López-Pousa A, Martín Broto J, Garrido T and Vázquez J: Giant cell tumour of bone: New treatments in development. Clin Transl Oncol 17: 419-430, 2015.

33. Chawla S, Henshaw R, Seeger L, Choy E, Blay JY, Ferrari S, Kroep J, Grimer R, Reichardt P, Rutkowski P, et al: Safety and efficacy of denosumab for adults and skeletally mature adolescents with giant cell tumour of bone: Interim analysis of an open-label, parallel-group, phase 2 study. Lancet Oncol 14: 901-908, 2013

34. National Institutes of Health: Common Terminology Criteria for Adverse Events (CTCAE) Version 4.0. http://evs.nci.nih.gov/ftp1/ CTCAE/CTCAE 4.03 2010-06-14 QuickReference 5x7.pdf

35. Rutkowski P, Ferrari S, Grimer RJ, Stalley PD, Dijkstra SP, Pienkowski A, Vaz G, Wunder JS, Seeger LL, Feng A, et al: Surgical downstaging in an open-label phase ii trial of denosumab in patients with giant cell tumor of bone. Ann Surg Oncol 22: 2860-2868, 2015

36. Bukata SV, Sudan M, Mendanha W, et al: Considerations for long-term maintenance treatment with denosumab for stable inoperable Giant Cell Tumor: Making a case for spacing of doses after initial response. Connective Tissue Oncology Society: Abstract 047, 2015. 